\title{
Decisions about restorative dental treatment among dentists attending a postgraduate continuing professional development course
}

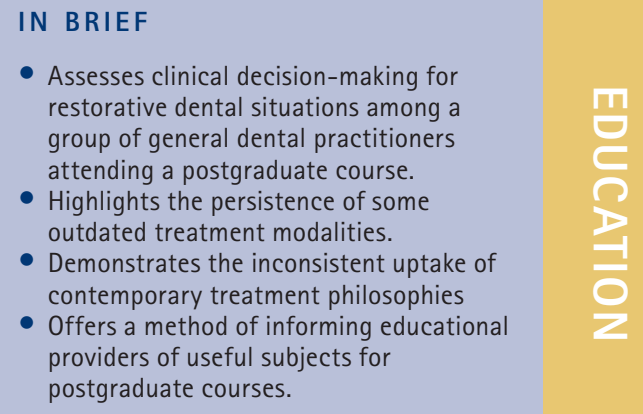

\author{
Y. Maidment, ${ }^{1}$ K. Durey ${ }^{2}$ and R. Ibbetson ${ }^{3}$ \\ VERIFIABLE CPD PAPER
}

Continuing professional development (CPD) courses seek to inform, educate and develop practitioners' patterns of prescribing in line with the evidence base. When devising such courses it would be useful for organisers to have some idea of what current practice is and the decision-making process as this would inform the development of appropriate continuing education courses. A questionnaire comprising ten questions was given to 90 dentists at the start of a day's lecture course run under Section 63 regulations. The dentists were then shown a series of pictures and asked how they would manage each of the cases presented. Eighty-nine dentists completed the questionnaire and the results were tabulated and fed back to the group at the end of their day's course. Results showed varied and inconsistent application of advances in restorative techniques among the respondents. Despite a definite interest in more modern treatment options, many practitioners continued to support the use of traditional techniques that could be considered outdated. Further investigation of the practices of GDPs and their decision-making processes would be useful in targeting postgraduate education programmes to encourage the uptake of evidence-based practice.

\section{INTRODUCTION}

Continuing professional development (CPD) courses seek to inform, educate and develop practitioners' patterns of prescribing in line with the evidence base. This may include the introduction of new materials and methods or the modification of existing procedures. It has been shown that the translation into practice of techniques and principles described at CPD meetings varies between individuals. ${ }^{1}$ Courses appear to have more impact if the subject matter is targeted to address individual learning needs. To maximise the benefit of CPD, general dental practitioners (GDPs) have a role to play in selecting the courses most relevant to them by way of critical personal review. In addition, when devising courses it would be useful for organisers to have

\footnotetext{
${ }^{1 * G e n e r a l ~ D e n t a l ~ P r a c t i t i o n e r, ~ E d i n b u r g h ; ~}{ }^{2}$ Specialist Registrar in Restorative Dentistry, Leeds Dental Institute, Clarendon Way, Leeds, LS2 9LU; ${ }^{3}$ Professor of Primary Dental Care \&t Director, Edinburgh Postgraduate Dental Institute, Lauriston Building, Lauriston Place, Edinburgh EH3 9HA

*Correspondence to: Dr Yann Maidment

Email: yannmaidment@blueyonder.co.uk
}

\section{Refereed Paper}

Accepted 17 June 2010

DOI: 10.1038/sj.bdj.2010.979

${ }^{\circledR}$ British Dental Journal 2010; 209: 455-459 some idea of what current practice is and the decision-making process behind it. ${ }^{2}$

Authors in Sweden and Germany surveying GDPs' treatment concepts for endodontically treated teeth found that practices were not in complete agreement with current recommendations in the literature. ${ }^{3,4}$ Although the current practices of GDPs in the UK have been surveyed, 5,6 there is little published work relating these to the uptake of modern restorative principles. ${ }^{7}$ Previous efforts have been made to look at how and why dentists decide to replace an existing amalgam restoration with a larger one or with a crown ${ }^{8-10}$ but advances in bonding technology may have rendered these findings obsolete.

The concept of minimum intervention to treat or repair damaged teeth is not new. ${ }^{11}$ This is an extension of a principle first suggested 20 years ago that operative intervention is not necessarily the treatment of first choice for carious teeth. ${ }^{12}$ Developments in adhesive dentistry have provided clinicians with more options, helping them to restore teeth without destructive preparations and repair restorations rather than replacing them, minimising the loss of sound tooth tissue. . $^{13,14}$
The aim of this article is to describe the reported decisions of a group of primary care dentists in relation to several clinical scenarios requiring material selection and choices of intervention.

\section{METHOD}

Ninety primary care dentists attending a one day postgraduate course on the subject of the restoration of an endodontically treated tooth were issued with a questionnaire comprising of ten questions devised by the authors (Fig. 1). The dentists were then shown a series of pictures and asked to answer questions about how they would manage each of the clinical situations presented. The purpose was to investigate treatment planning decisions and material choices in several scenarios involving restorative dentistry including the management of carious lesions, restoration of fractured and heavily restored teeth and the replacement of missing teeth.

Answer sheets were collected and the responses tabulated and fed back to the participants at the end of the day.

\section{RESULTS}

Eighty-nine dentists out of 90 attending 
the course completed questionnaires. Responses to specific questions that were unusable or missing were classified as missing.

Figure 1 shows the questionnaire with nine questions alongside the responses for each question. Question 10 asked about the choice of material when fabricating a core for a successfully root-treated upper 7: the results for this question are shown in Table 1.

\section{DISCUSSION}

The dentists attending the course were all primary care practitioners working within either the General Dental Service or the Salaried Primary Service. One third of the attendees were vocational dental practitioners or general professional trainees from the Southeast region of Scotland. No demographics were recorded regarding their dental school of origin, their date of qualification or any additional qualifications held. The results from the questionnaire were tabulated during the day and were reported back to the participants at the end of the day, which produced constructive discussion.

The results of this questionnaire suggest varied uptake and application of evidencebased dentistry and recent advances in restorative techniques.

A number of the group indicated a willingness to use new materials and explore more complicated options. For example, the majority were happy to place a posterior composite restoration to improve aesthetics and 44\% would suggest an implant to replace a missing lower first molar compared with just 13\% opting for bridge work.

Although some GDPs seemed open to newer options, there was an indication that older techniques prevailed in some circumstances. The results from Question 1 indicate that a large proportion of the practitioners remain restoratively driven despite the increasing emphasis placed on preventive dentistry. It is established that arrest of superficial approximal carious lesions, such as that described, is possible given the existence of an environment promoting remineralisation. Despite this over 30\% of these primary care practitioners elected to restore, committing the tooth to the restorative cycle.

Techniques considered outdated in many circles were identified as still being

\section{Fig. 1 Questionnaire with tabulated results as completed by GDPs}

\section{A bitewing radiograph taken two years ago} revealed an enamel lesion in the distal surface of the maxillary right second premolar in a 30 -yearold patient. A second bitewing, below, shows the same tooth two years later with the lesion just into dentine (D1). There is also a clinical picture of the maxillary arch.
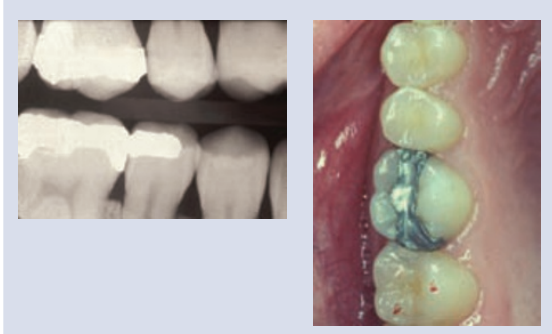

2. The patient has had this MOD amalgam restoration in their first maxillary premolar for 20 years. They wish to have the restoration replaced with a tooth coloured restoration. The cavity is of moderate depth only and the tooth is vital and caries free.

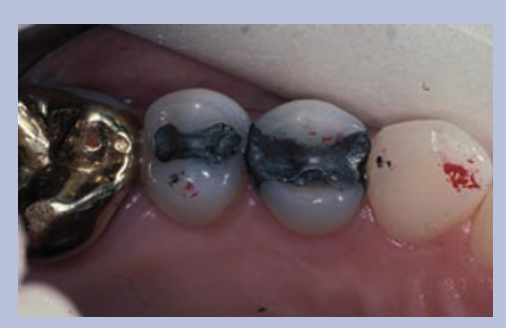

3. This 50-year-old patient has recently fractured the mesio-buccal cusp of his mandibular right second molar tooth. The tooth is caries free and vital.

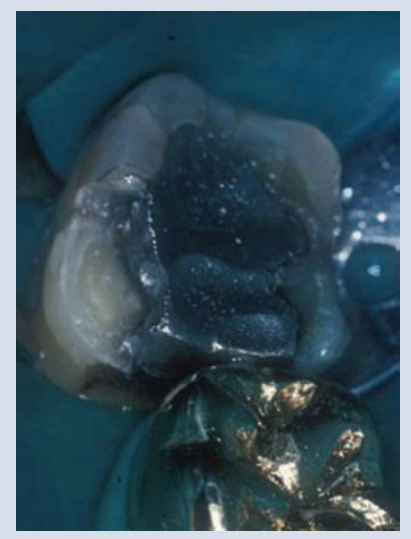

4. The first maxillary molar has been satisfactorily root-treated and restored with an amalgam restoration retained predominantly by the pulp chamber. Aesthetics are not a concern.

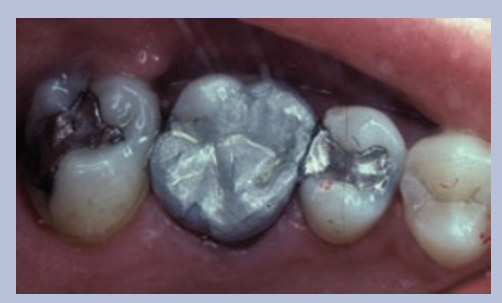

\section{Would you:}

a) Restore this tooth?

b) Manage the caries preventively?

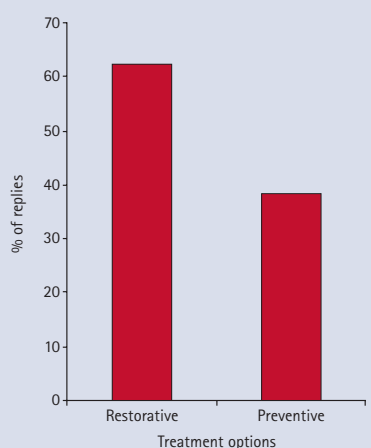

Would you be happy to provide a directly placed composite restoration for this tooth?

a) Yes

b) No

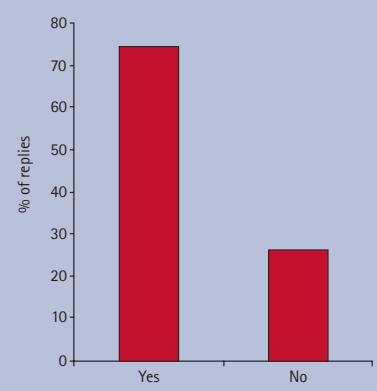

In order to restore the tooth, would you:

a) Replace the entire restoration and restore the buccal cusp?

Or:

b) Repair the tooth by adding to the existing restoration?

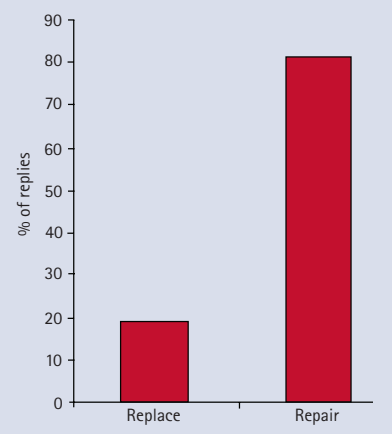

Would you provide a crown for this tooth? a) Yes

b) No

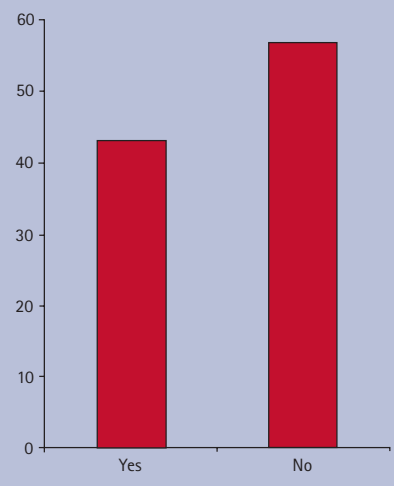


5. This 40-year-old patient has fractured the palatal cusp of her upper left second premolar tooth. The fracture line ends level with the palatal gingival crevice.

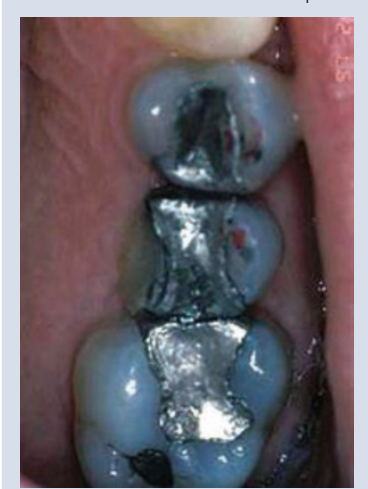

6. The extensively damaged but vital mandibular first molar has lost three cusps and significant amounts of tooth structure but is caries free. Additional (auxiliary) retention is needed to retain an amalgam restoration.

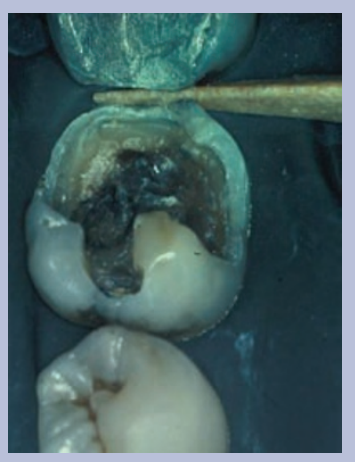

Would you restore this vital, caries-free tooth with:

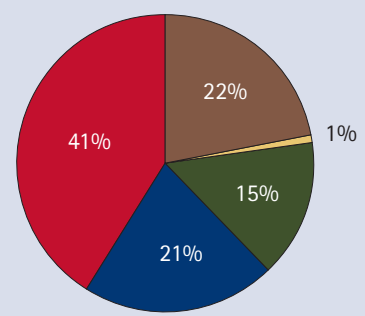

Amalgam

Direct composite resin restoration

Adhesive indirect composite or porcelain restoration

Porcelain fused to metal crown

$\square$ Glass lonomer Patch

\section{Would you use:}

a) Cavity design features alone?

Or:

b) Cavity design features and dentine pins?

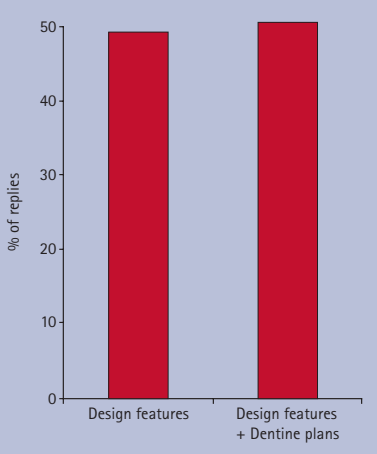

Additionally the dentists were asked to select a lining material for use in this situation. These results are displayed in the table below:

\begin{tabular}{l|l}
\hline Base Lining Material & Number of GDPs \\
\hline Calcium hydroxide & 26 \\
\hline Calcium hydroxide $+2^{\circ}$ base & 22 \\
\hline Resin-modified Glass ionomer cement & 14 \\
\hline Glass ionomer cement & 10 \\
\hline Zinc oxide - eugenol & 7 \\
\hline Etch \&t adhesive/bonding agent & 5 \\
\hline Zinc phosphate & 2 \\
\hline Others & 3 \\
\hline Nothing & 1 \\
\hline
\end{tabular}

7. This 35-year-old patient would like a bridge to replace her missing maxillary incisors. There is an inadequate volume of bone for implant placement; the maxillary canines are vital and there is canine guidance on mandibular excursions. There are no financial restrictions.

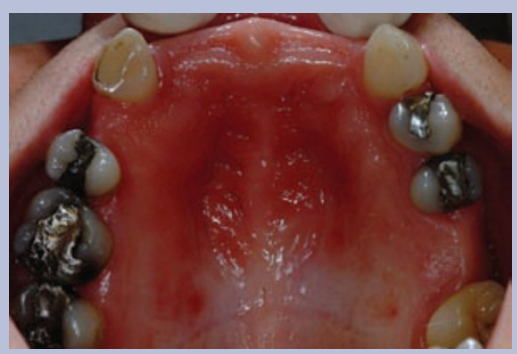

Would you be happy to provide this?

$\begin{array}{ll}\text { a) Yes } & \text { b) No }\end{array}$

If yes, would the bridge:

a) Use full crowns as retainers?

b) Ne a resin-retained bridge?

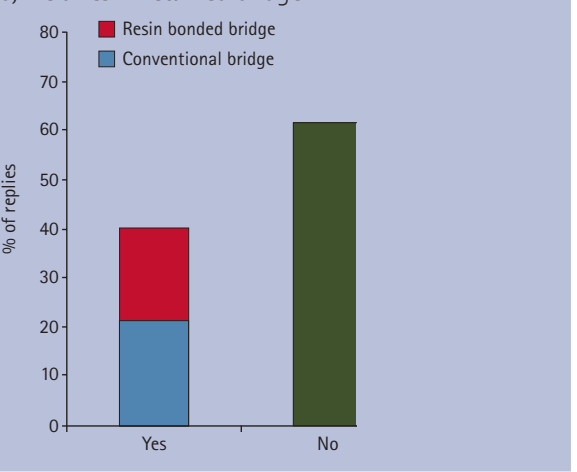

Table 1 Results for question 10: choice of material when providing a core for a successfully root-treated upper 7

\begin{tabular}{l|l} 
Material for core fabrication & $\begin{array}{l}\text { Number } \\
\text { of GDPs }\end{array}$ \\
\hline Amalgam & 44 \\
\hline Composite resin & 25 \\
\hline Cast gold & 9 \\
\hline Cermet & 3 \\
\hline Resin-modified glass ionomer cement & 4 \\
\hline Glass ionomer cement & 5 \\
\hline Left blank & 1
\end{tabular}

common practice by this questionnaire. For example, the choice of lining and base materials (Question 6) seemed to be based more on familiarity rather than evidence. Over 50\% of respondents chose calcium hydroxide with or without a secondary base despite the lack of evidence regarding its effectiveness. ${ }^{15} \mathrm{~A}$ further example of the continued use of outmoded techniques was provided by the answers to Question 6 which asked about the development of auxiliary retention in a large posterior cavity. A cavity of these dimensions was selected as it would have been less appropriate to restore it with directly placed composite $\operatorname{resin}^{16}$ and therefore it was a reasonable question to ask specifically about the retention for silver amalgam. Half of the practitioners chose to use dentine pins in addition to cavity design features to aid retention of the large amalgam. This was despite ample coverage in the peer reviewed journals that there is no indication for their continued use and evidence that they carry significant disadvantages producing stresses within the teeth while also weakening restorative materials. ${ }^{17,18}$ The use of pins may be a reflection of the system in which practitioners work. Pins were supported previously by NHS regulations in England and Wales and still are in Scotland. In this respect the NHS system of remuneration has come under criticism for failing to support best practice. ${ }^{19}$

There was also variable adaptation of older techniques in line with current evidence. For example the repair of fractured amalgam restorations where possible, in contrast to their replacement, is considered to be advantageous. Properties of such repaired restorations are favourable ${ }^{20}$ 
and the technique minimises further loss of tooth tissue. The majority of the participants applied this principle when restoring the fractured cusp adjacent to a Class 2 amalgam restoration (Question 3) but not to a fractured occlusal restoration (Question 9). These decisions might have been more related to the complexity and time required to carry out the procedures.

There continues to be a shortage of evidence in the literature defining the efficacy of many restorative procedures. However, the results of this study indicate that even where evidence is available, clinicians are frequently reluctant to apply it. The majority of clinicians elected to accept a root filled molar tooth (Question 4) with a large complex amalgam filling as being definitively restored, despite evidence that crowning molar teeth following endodontic treatment results in less repeated intervention. ${ }^{21}$ This particular decision is not limited to this particular group of dentists. Virtually identical results were recorded in the report of Scurria et al..$^{22}$ in the United States. There is a number of possible reasons why dentists decide not to place an indirect restoration with cuspal coverage to protect an endodontically treated posterior tooth. It is possible that when a dentist suggests that a crown might be beneficial, the patient declines on financial grounds or time constraints. However, in this study these would not have been factors in the decision-making process but there is evidence that a dentist's own clinical experience, particularly if it is recent, may be an influence; ${ }^{23}$ alternatively it might be that the practitioner is simply not aware of the evidence available. A further possibility was that the decision not to provide a crown was based on the wish to conserve tooth structure but if so, this principle was not consistently applied in the answers to Question 5.

In Question 5, participants were shown a maxillary second premolar restored with an MOD amalgam where the palatal wall of tooth structure had fractured and been lost. The underlying question posed by the clinical situation was how not only to restore the missing tooth structure but also to protect what remains while satisfying functional and the aesthetic requirements. It was encouraging that only $15 \%$ chose amalgam while the $20 \%$ who selected directly placed composite resin would have produced a bonded
8. This patient is missing the mandibular left and right first molars in otherwise intact arches. The patient wishes the left first molar to be replaced as she feels that its absence makes chewing difficult but she does not notice the absence of the right molar. The teeth are only moderately restored and vital with good periodontal support and the plaque control is good.
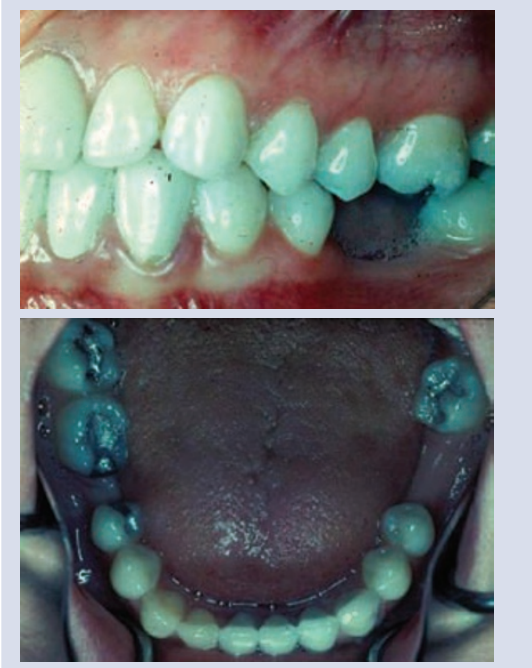

9. The distal portion of this occlusal amalgam restoration has been lost. The cavity is caries free.

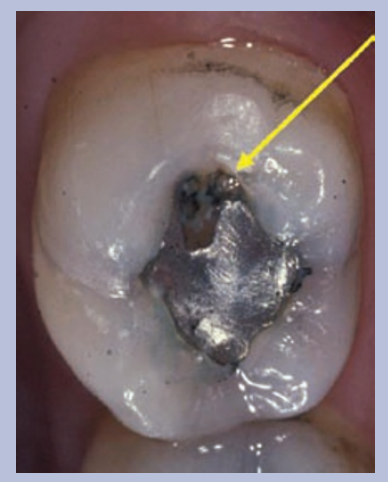

restoration which might have protected the remaining buccal cusp. However, it is a major clinical challenge to recreate cusps in composite resin while the dimensions of the restoration would be likely to affect its longevity adversely. ${ }^{24}$

The $20 \%$ of respondents who decided to provide a porcelain-fused-to metal crown would have removed most of the residual coronal dentine in making the preparation. It was therefore encouraging to see that $40 \%$ selected an indirect composite resin or porcelain restoration. If this had been provided as an onlay as compared with a full crown, dentine would have been preserved at the base of the buccal cusp while giving the benefits of cuspal coverage: it would have been useful to ask the question in such a way as to discriminate between an inlay and an onlay. Interestingly the responses to this question did not seem to
Would you recommend:

a) An implant

b) A bridge

c) No treatment?

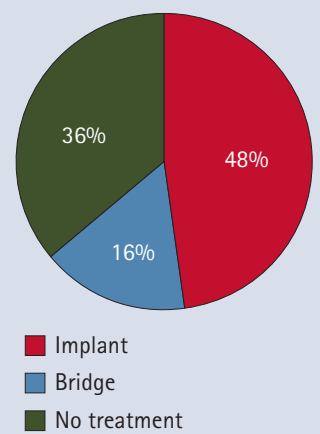

Would you repair or replace this restoration?

a) Repair

b) Replace

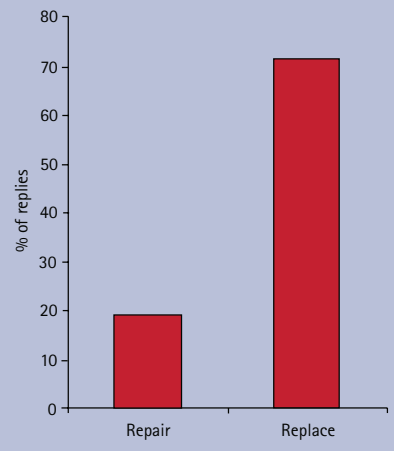

have been influenced by the NHS regulations as they apply in Scotland where indirect composite resin and ceramic inlays/ onlays are not supported by the fee schedule. This is in contrast to the discussion on the use of dentine pins in Question 6.

In Question 7, the clinicians were asked to make a choice between a resin-retained bridge and one using crowns as the retainers. Over half elected for a design using crowns as the retainers in preference to the more minimally invasive choice of a resin-retained bridge. This might have been because of an awareness of the literature indicating that longer span resin-retained bridges carry a higher failure rate ${ }^{25}$ or perhaps participants' personal experience of their performance. However, those who chose to use full coverage crowns as the retainers ignored the significant gingival recession on the facial aspects of the 
prospective abutment teeth which would have made full crown preparations highly destructive and potentially very damaging to the teeth.

The final Question (10) asked participants about their choice of core material for a root treated maxillary second molar which had little by way of a pulp chamber and $2 / 3$ of the palatal wall being all that remained of the coronal tooth structure. Cores of this size are structural in respect of the need to support the crown. In such situations, logic would dictate that the material with optimal physical properties is selected. Well over $2 / 3$ of the respondents chose silver amalgam or composite resin, with amalgam being preferred by $2 / 3$ of this sub-group. A relatively low number of individuals selected a glass ionomer cement or variant of this material, which showed a good appreciation of its relatively poor performance when used in bulk as a core to support a crown. ${ }^{26}$

The results of this study indicate considerable variation in decision-making among primary care dentists. It appears that many continue with familiar techniques, despite widely disseminated evidence that they should change their practice. They may be operating within their 'comfort zones' based on anecdotal success. This raises questions of how best practitioners may be encouraged to develop new knowledge and apply it. In a busy clinical environment, introducing new techniques is difficult and they will initially take longer than more familiar ones. There is also the likelihood that initial use of a new technique or material may result in poorer results. Both of these factors do not encourage change. Undoubtedly, continuing education courses which contain a practical or 'Hands-on' component are essential in allowing dentists to rehearse new clinical techniques before providing them for their patients.

There are obvious limitations in treatment planning and decision-making using only photographs and a restricted patient history. As a result the specific findings of this questionnaire should be considered with some caution. Additionally the subjects were not chosen randomly, they had self-selected to attend this postgraduate course presumably either because they were interested in the subject or perceived a learning need. There was also no analysis of the environment in which the practitioners worked, a variable that may affect clinical practice for financial and legislative reasons. Further research using a larger randomised group of individuals would provide a better indication of the decision-making processes and techniques used by practitioners. This could help to inform those devising postgraduate courses as well as demonstrating the level of uptake of evidence-based techniques and the success of CPD activities.

\section{CONCLUSIONS}

While a substantial proportion of those attending the course displayed willingness to embrace aspects of modern evidence-based dentistry, the application of the evidence was inconsistent. A modern approach, based on minimal intervention and preservation of tooth tissue was only partially evident. Considerable reliance was still placed on traditional techniques although there was definite interest in more modern treatment options.

The use of a brief questionnaire of this type was considered useful in assisting identification of areas of educational need. Further investigation of the practices of GDPs and their decision-making processes would be useful in targeting postgraduate education programmes and assessing continuing professional development. This may promote the translation of new principles into the working environment.

1. Firmstone $V \mathrm{R}$, Bullock A D, Fielding A et al. The impact of course attendance on the practice of dentists. Br Dent J 2004; 196: 773-777.

2. John V, Parashos P. Factors involved in the translation of continuing professional development programmes into clinical practice among Victorian dentists. Aust Dent J 2007; 52: 305-314.

3. Eckerbom M, Magnusson T. Restoring endodontically treated teeth: a survey of current opinions among board-certified prosthodontists and general dental practitioners in Sweden. Int J Prosthodont 2001; 14: 245-249.

4. Naumann M, Kiessling S, Seemann R. Treatment concepts for restoration of endodontically treated teeth: a nationwide survey of dentists in Germany. J Prosthet Dent 2006; 96: 332-338.

5. Brunton P A, Christensen G J, Cheung S W, Burke $\mathrm{FJ}$, Wilson N H. Contemporary dental practice in the UK: indirect restorations and fixed prosthodontics. Br Dent J 2005; 198: 99-103, discussion 89.
6. Wilson N H, Christensen G J, Cheung S W, Burke F J Brunton P A. Contemporary dental practice in the UK: aspects of direct restorations, endodontics and bleaching. Br Dent J 2004; 197: 753-756, discussion 747.

7. Seow $L L$, Toh C G, Wilson N H. A survey of current practices among general dental practitioners in Manchester in 2002. Prim Dent Care 2003; 10: 87-92.

8. Annusavice K. Clinical decision making and cost effectiveness: impact on treatment choices. In: Quality evaluation of dental restorations: criteria for placement and replacement. pp 389-397. Chicago: Quintessence, 1989.

9. Maryniuk G, Schweitzer S, Braun R. Replacement of amalgams with crowns: a cost-effectiveness analysis. Community Dent Oral Epidemiol 1988; 16: 263-267.

10. Annusavice K. Treatment regimens in preventive and restorative dentistry. J Am Dent Assoc 1995; 126: 727-743.

11. Burke F J. From extension for prevention to prevention of extension: (minimal intervention dentistry). Dent Update 2003; 30: 492-498, 500, 502

12. Elderton R. Assessment and clinical management of early caries in young adults: invasive versus noninvasive methods. Br Dent J 1985; 158: 440-444.

13. Moncada G, Fernández E, Martín J et al. Increasing the longevity of restorations by minimal intervention: a two-year clinical trial. Oper Dent 2008; 33: 258-264.

14. Burke F J T, Cheung W, Mjor I, Wilson F. Restoration longevity and the analysis of reasons for the placement and the replacement of restorations provided by vocational dental practitioners and their trainers in the UK. Quintessence Int 1999; 30: 234-242.

15. Murray P E, Hafez A A, Smith A J, Cox C F. Bacteria microleakage and pulp inflammation associated with various restorative materials. Dent Mater 2002; 18: 470-478.

16. Barnardo M, Luis $H$, Martin M D et al. Survival and reasons for failure of amalgam versus composite posterior restorations placed in a randomised clinical trial. J Am Dent Assoc 2007; 138: 775-783.

17. Pameijer $C H$, Stallard R E. Effect of self-threading pins. J Am Dent Assoc 1972; 85: 895-898.

18. Dilts W E, Welk D A, Laswell H R, George L. Crazing of tooth structure associated with placement of pins for amalgam restorations. J Am Dent Assoc 1970; 81: 387-390.

19. Lucarotti $K$, Holder L, Burke F J T. Outcome of direct restorations placed within the general dental services in England and Wales (Part 1): variation by type of restoration and re-intervention. J Dent 2005; 33: 805-815.

20. Cipriano T M, Santos J F. Clinical behaviour of repaired amalgam restorations: a two-year study. J Prosthet Dent 1995; 73: 8-11.

21. Kolker J L, Damiano P C, Caplan D J et al. Teeth with large amalgam restorations and crowns: factors affecting the receipt of subsequent treatment after 10 years. J Am Dent Assoc 2005; 136: 738-748, quiz 805-806.

22. Scurria M S, Shugars D A, Hayden W J, Felton D A. General dentists' pattern of restoring endodontically treated teeth. J Am Dent Assoc 1995; 126: 775-779.

23. Bader J D, Shugars D A. Understanding dentists' restorative treatment decisions. J Public Health Dent 1992: 52: 102-110.

24. Van Nieuwenhuysen J P, D'Hoore W, Carvalho J, Qvist $V$. Long-term evaluation of extensive restorations in permanent teeth. J Dent 2003; 60: 325-329.

25. Djemal S, Setchell D, King P, Wickens J. Long-term survival characteristics of 832 resin-retained bridges and splints provided in a post-graduate teaching hospital between 1978 and 1993. J Oral Rehabil 1999; 26: 302-320.

26. Cohen B I, Mark K, Pagnillo M K et al. Cyclic fatigue testing of five endodontic post designs supported by four core materials. J Prosthet Dent 1997; 78: 458-464. 
